\title{
THE EFFECTS OF SOCIAL MEDIA AND HASHTAG ACTIVISM ON ENHANCING STUDENT VOICE TO CREATE INSTITUTIONAL CURRICULUM CHANGES
}

\author{
Michelle Nguyen
}




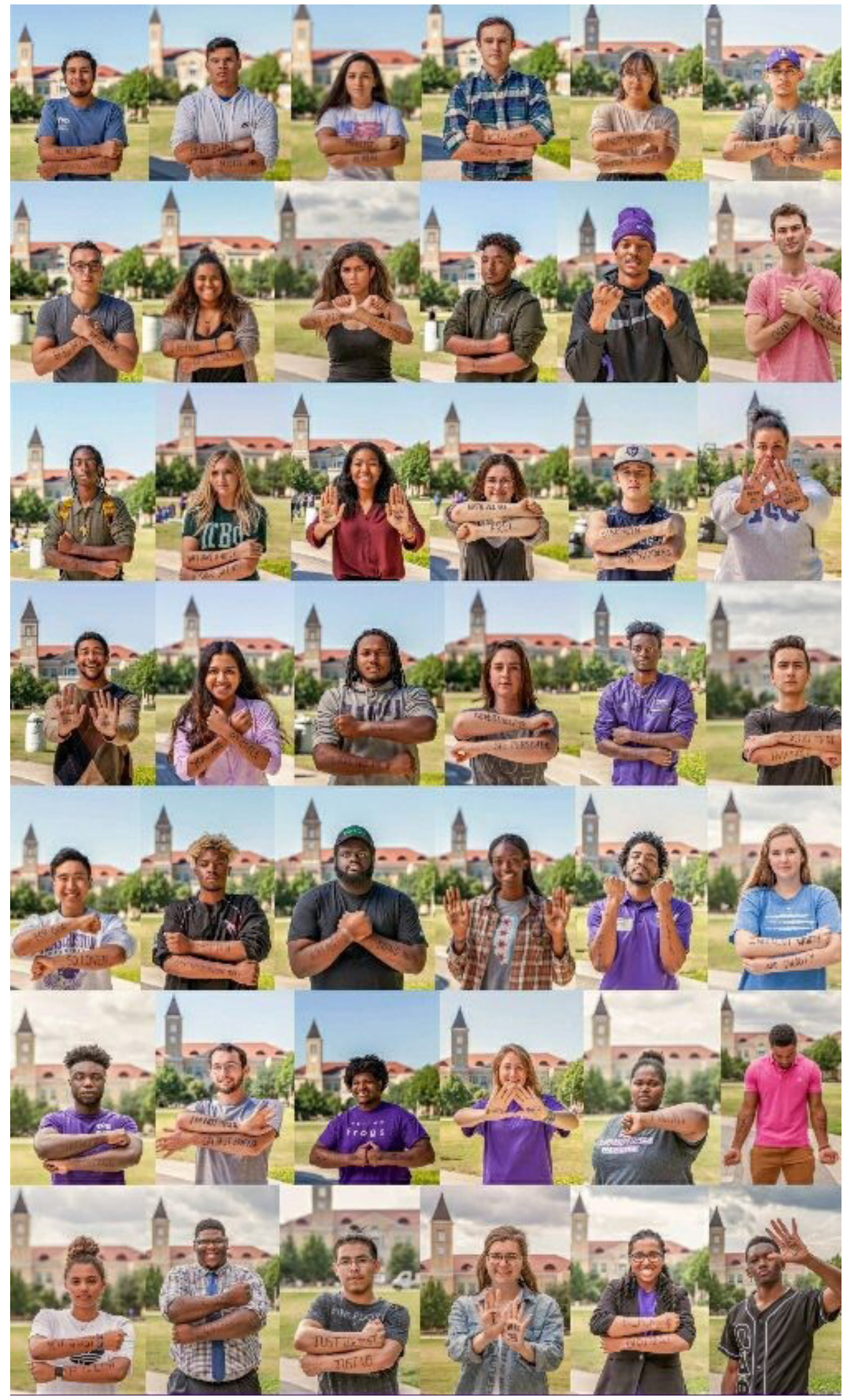


On Friday, October 26th 2018, students lined up to take pictures with words written across their bodies to express their concerns about TCU. Later in the week, these pictures were uploaded onto social media, specifically Twitter and Instagram, in an attempt to gain the attention of administration. These images were edited to all look uniform, set up on a Dropbox, and sent out on the morning of November 7th 2018 to the students who participated, with explicit details to post at 7:00 PM that night. At this exact moment, hundreds of tweets and Instagram posts filled people's timelines, revealing how many TCU students stand in solidarity with one another, all stating their concerns with inclusiveness on campus and calling out TCU for their lack of diverse and equitable initiatives, by addressing “Dear TCU."

\section{INTRODUCTION}

Texas Christian University (TCU) is a private liberal arts university in Fort Worth, Texas. It is founded under the Disciplines of Christ and has a majority white and conservative student population. According to the TCU 2018 Fact Book, the undergraduate student population currently consists of sixty-eight point one percent white students and thirty-two point nine percent students of color. The administration, faculty and staff mirror the student population's demographics. Seventy-eight point seven percent (78.7\%) of faculty and staff are white, while only twenty-one point three percent $(21.3 \%)$ are of color. Being the only student visibly different from peers can be an uncomfortable experience. Students of color not only feel excluded in social settings, but also in classroom settings too, due to the lack of diversity present on campus. The keyterm "stereotype threat" describes the experience of many marginalized students who "[are] concerned about being judged or treated negatively on the basis of [a] stereotype" (Spencer, Logel \& Davies, 2016, p. 416). Stereotype threat can affect a student's sense of belonging because in professional and academic settings, "people whose groups are stereotyped or otherwise stigmatized tend to be uncertain of the quality of their social bonds" and can make students feel isolated (Spencer, et al., 2016, p. 424). Students have made strides towards improving TCU and the experience of students in marginalized populations on campus by utilizing social media to demand change from administration.

Technology filters into every part of a young adult's daily life: checking social media to catch up with friends, experiencing digitally mediated lessons in the educational classroom, and even engaging online with social movements and protests, are daily activities for current, college-age students. A majority of students' engagement with online social movements, however, falls into 
a category known as "hashtag activism," which is a type of protest and act of resistance that is united on social media through a hashtagged word or phrase (Yang 2016). A few examples of hashtag activism are: \#BlackLivesMatter, \#BringBackOurGirls, \#LoveWins, and many more. Hashtags are easy to navigate on many social media forms and have the ability to connect many posts from different people under one categorized umbrella. Aaron Noland (2017) completed studies on young adults and their influence with digital activism and notes how youth are influential and proficient users of social media, in addition to being more willing to find a passion that directs their lives. Young people have been, for many decades, at the forefront of progressive social movements like this, and today is no different. In my experience as a college student in the United States starting in 2015, I have seen the level of impact students my age, or younger, were able to make with their zeal towards fighting against social injustice. These can range from national campaigns, such as concerns with climate change or police brutality, while others are more specific to the community in which individuals are situated. However, these localized examples of activism often reflect larger social issues, combining national and global perspectives into a local community-focused perspective. When reflecting on my experience attending TCU, even though I knew the school was not unique to being affected by national higher education concerns, I did not see as many large protests as I saw attempts at pointing out injustice at TCU in an online manner.

For many students, "social belonging, or a sense of connection to or relationship with others, has been proposed as a human need" (Fleming, Oertle, Plotner, \& Hakun, 2017). Whether a student is disabled or a student identifies as queer, for example, a lack of sense of belonging can inhibit the success of a student at college. The point of protest, especially on college campuses, is to bring light to an issue that is affecting the well-being of a specific group of individuals. Anyone can take a second to look up the Twitter hashtags \#DearTCU or \#BeingMinorityAtTCU and find the negative experience that some students have of the university because they do not feel like they are being supported in their daily lives. The administration and the Board of Trustees are aware of students' presence on social media, because they recognize that this is a way to gauge how students are feeling, which can be exemplified by hashtag social media movements, and has led the way for curricular changes at TCU. 


\section{BACKGROUND OF HASHTAG ACTIVISM}

Today, fifty-six percent (56\%) of the U.S. population carries smartphones, which provides a foundational basis for why people are turning to social media as platforms for organizing (Bonilla \& Rosa, 2015). Social media, by definition, is a way to build connections across social boundaries that might have typically inhibited people from getting together. Such barriers include, but are not limited to, geographical location, cultural differences, or a lack of resources to get connected to others. College-aged students have been major stakeholders in many past social movements, such as the Free Speech Movement, the lunch counter sit-ins to push for desegregation in Greensboro, North Carolina in the sixties, and organizing campus campaigns for various social issues, such as women's reproductive rights and immigration rights (Earl, Maher, \& Elliot, 2017). It is no surprise that college students are a large portion of participators in hashtag activism of the twenty-first century.

Twitter, as a form of social media, utilizes hashtags the most. Hashtags within Twitter allow information to be spread wide and amplified across social media, which is especially useful for fighting for social change (Ofori-Parku \& Moscato, 2018). For example, the protests over Michael Brown's death by law enforcement surfaced on Twitter as \#Ferguson. In the month after the first \#Ferguson tweet appeared, there were more than eight million instances of \#Ferguson on the site (Bonilla and Rosa, 2015). The "trending" feature on Twitter allows users to see which tweets are being used the most at the moment, and there is no doubt that \#Ferguson appeared on that list multiple times.

Twitter, hashtag activism, and other aspects of social media are especially salient to marginalized and oppressed people because they are, and historically have been, most likely to be portrayed negatively in the media. Marginalized populations are able to redefine their own stories and voices by organizing on social media. In the case of Michael Brown, many people were outraged by his death, and were especially horrified after having seen the video of his wrongful death, which circulated on social media. The tweet that popularized this video was captioned with the phrase "I just saw someone die." Many people saw his death as an unfair shooting of a Black man by a police officer, and they were motivated to speak up about this perspective. When people of color protest in the streets, however, it is often seen as "looting" and "rioting" by news and media outlets. Media is powerful and can impact societal attitudes, so when media outlets decide to portray people of color in a derogatory light, those actions are harmful to entire communities of color. For example, news 
coverage of Hurricane Katrina encouraged racial stereotypes by captioning an image of a Black male as presumably "looting," while a seemingly comparable white couple were just "finding food" (Sommers, Apfelbaum, Dukes, Toosi, \& Wang, 2006, p. 40). Social media gives the control to the people who utilize it, as opposed to having their content or images manipulated by other media sources. Transitioning their organizing online allows social activists' actions to be more transparent and less tainted (Bonilla and Rosa, 2015, p. 8).

The idea of reclaiming and redefining narratives is essential to digital and hashtag activism. People can lend their personal narratives as contributions to a much larger critical conversation about an issue as soon as they add the hashtag into their tweets. Yang Xiong (2016) explains how the narrative agency in hashtag activism allows individuals to create stories on social media that are collective and recognized by the public. Stories of social justice activists from all over the world can be brought to any individual Twitter user with a simple search in the Twitter search bar for a hashtag. The connectedness of hashtags provides a perfect space for youth to organize across various social media outlets. Social media is accessible. Providing politically engaged young people with a space to become active participants in protests, social media connects users across the world with others who are interested in similar issues-all without putting up traditional barriers that might prevent someone from being involved (Stronaiuolo \& Thomas, 2017). TCU students, like many college students, are active on various forms of social media. The high level of social media engagement by young people explains why many of TCU's most recent attempts at student activism have been centered on online social platforms, specifically Twitter and Instagram. As noted earlier, the majority of students on campus are white, perpetuating a "white space," where students of color are forced to navigate the norms of the majority racial group. Social media and online activism allow many marginalized populations to connect with students outside of this "white space" campus culture. Due to TCU's predominantly white population, many people of color might feel like "intruders" into this "white space" (Van Dyke \& Tester, 2014, p. 293). TCU student activists have utilized hashtags to bring attention to their concerns, and to take a step outside of the "white space" of the campus. Two examples of hashtags, \#BeingMinorityAtTCU and \#DearTCU, were put to use for social activism, in 2016 and 2018, respectively, and are the center of my thesis. 


\section{\#BEINGMINORITYATTCU}

In October of 2016, numerous tweets appeared on Twitter using the hashtag \#BeingMinorityAtTCU. These tweets were mostly posted by students of color noting singular moments on the TCU campus that have shaped their experience. Most of the tweets represented microaggressions that students often faced, chronicling singular moments of this modern-day subtle form of racism (Minikel-Lacocque, 2012). Through this hashtag, with the exception of a few tweets, students explained moments in which they were discriminated against or negatively impacted because of their identity as a student of color. It is important to note that the experiences students expressed were not always overt forms of racism. Instead, many posts were about microaggressionsracist actions that, even though they may even come from well-intentioned peers, end up accumulating to make students of marginalized populations feel excluded and like they do not belong (Figure 1). \#BeingMinorityAtTCU grew from a single tweet into an impromptu movement because many other students were experiencing the same situations. There was no specific organization behind the movement-it was a result of one student expressing an experience and many other students identifying with the hashtag. The resulting mass of tweets got the attention of TCU administration.

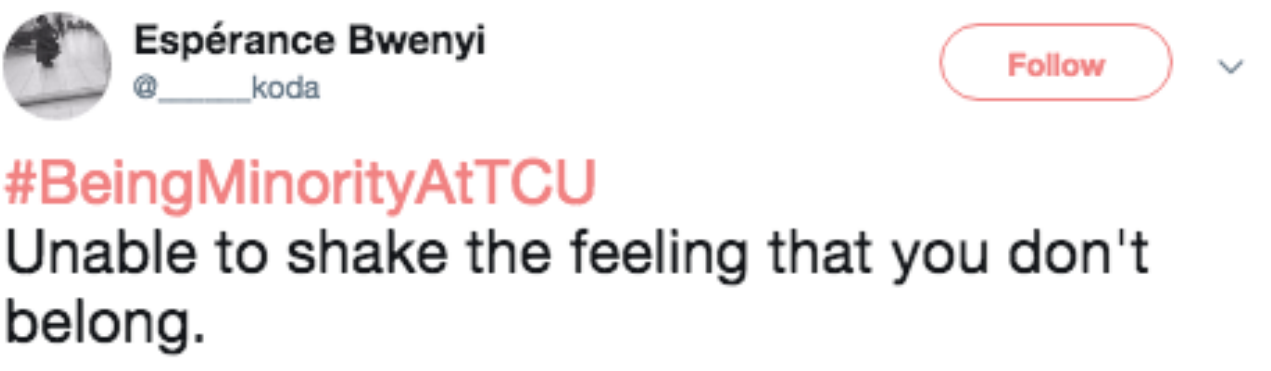

7:28 PM - 18 Oct 2016

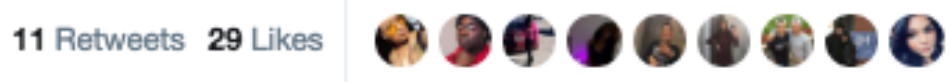

$2 \quad \uparrow 7 \begin{array}{llll}11 & & 29\end{array}$

Figure 1. @_koda using the \#BeingMinorityAtTCU to express the overall feeling of not belonging on TCU's campus. 
Multiple articles covering the trending hashtag were written in different news sources such as TCU 360 (the student newspaper) and the Ft. Worth Star-Telegram (a local Fort Worth newspaper). Writing for TCU 360, Tamera Hyatte claimed that the hashtag \#BeingMinorityAtTCU went "viral" and became popular quickly, through reflecting "on the overt and subtle slights [that students of color] face on campus." Following this coverage, Chancellor Victor Boschini made an announcement that "he was creating a plan of action" (Hyatte, 2016).

TCU is not unique from other predominantly white institutions (PWIs). Nella Van Dyke and Griff Tester (2014) conducted research examining the levels of racial bias and racially-motivated hate crimes on college campuses. Van Dyke and Tester found that students of color were more often discriminated against on campuses that are more expensive to attend, have a large Greek-life population, and have a predominately white population (p. 302). These factors create ingrained social norms that cater to the majority population and often isolate students in marginalized populations. Jennifer Esposito completed studies investigating the effects of "hidden curriculum" of women of color at PWIs. Esposito defines "hidden curriculum," and specifically "hidden curriculum of diversity," as "the informal interactions and lessons students learn regarding gender, race, difference, and power" (2011, p. 143). TCU's high population of Greek-affiliated students and the high cost of tuition come together to create social expectations, or a "hidden curriculum," that creates an exclusive environment where marginalized students are taught that they are different and do not belong.

As I mentioned earlier in this paper, TCU is a predominately white institution with over fifty-one point nine percent (51.9\%) of its student population affiliated with a Greek organization. Figure 2 reveals the opinion of a male of color who was told not to go through traditional recruitment for the Interfraternity Council (IFC). IFC mainly appeals to white students and can enhance the isolation that students of color or other marginalized identities might feel. The higher the Greek population, the more relevant it is to the general student population. TCU's high percentage of Greek-life affiliated undergraduates filters into the daily lives of students, affiliated and unaffiliated alike, because of the high level of influence that Greek life has on the university. Students of color are taught, through recognizing social cues around them and through the statements of other students, that they should not partake in specific activities because of their identity. 


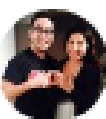

Oscah

@oscarisfierce

Follow

\title{
Being told I would be wasting time rushing IFC because they didn't take people of "race and orientation" \#BeingMinorityatTCU
}

\author{
8:53 AM - 19 Oct 2016
}

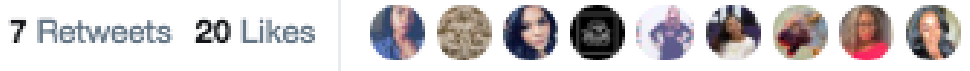

$\begin{array}{lllll}1 & \uparrow & Q_{20}\end{array}$

Figure 2. @oscarisfierce explaining a conversation, in which he is told not to go through Interfraternity Council recruitment because of his race and sexual orientation.

TCU's tuition is expensive. Not including room and board, tuition currently stands at about $\$ 49,160$ per academic year. A common stereotype that exists on TCU's campus is the idea that people of color can only afford to attend if they are a student athlete or a Community Scholar. Community Scholars, most of whom are students of color, come from select local high schools and are awarded a full-ride scholarship. Figures 3 reveals that students are aware of this stereotype, which affects their experience. This isolates and invalidates the experiences of students of color who are neither an athlete nor a Community Scholar and perpetuates this stereotype that people of color cannot afford to come to private universities like TCU. In Esposito's studies of "hidden curriculum," she notes how the hyper-visibility that many people of color experience creates this uncomfortable feeling that is salient to their daily experiences. Social isolation occurs in two ways. Students of color are not only presumed by their white peers to be at TCU only under a certain label, but also are physically segregated on campus due to the hyper-visibility of people of color. These conditions of social isolation combine to create TCU's "hidden curriculum" of not including people of color into the general student body. It should be noted that TCU's high cost of attendance, in addition to not meeting full financial need for all students, is exclusionary and part of the reason why there is a lack of diversity. However, the fact that this is a common assumption 
for the TCU population-that black students on campus only occupy the spaces of student athletes and Community Scholars-reveals the general student population's lack of understanding that there are students of color who exist outside of those two specific realms. Van Dyke and Tester would say that TCU students of color are most likely to experience a lack of belonging and experience more discrimination based on their race because they are forced into these boxes.

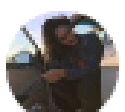

Gianna Mejia, CPhT

@theblackadorian

Follow

\section{Being assumed that you are either an athlete or community scholar in order to attend such an expensive school \#BeingMinorityatTCU}

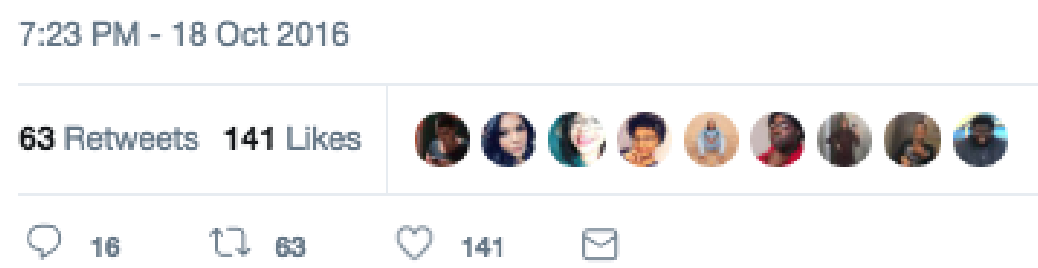

Figure 3. @theblackadorian talking about the comments that they receive because of the high expense of TCU's tuition.

Although \#Being MinorityAtTCU really only appealed to students of color, there were multiple white students who joined the conversation (Figure 4). No one really provided negative responses on Twitter to the students who tweeted \#BeingMinorityAtTCU. Most of the tweets using the hashtag either expressed their own personal experiences being a marginalized identity at TCU, or expressed support of those students. In addition, faculty and staff were also present in the online conversation to share their support and compare their experiences to students of color (Figure 5). \#BeingMinorityAtTCU called out TCU for not supporting students, faculty, and staff of color and opened up a space for white students to stand in solidarity with their peers of color. 


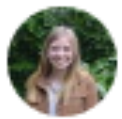

EmJ Hanaway

@emmyhanaway

\section{\#BeingMinorityAtTCU I'm listening \& I'm learning \& I'm thankful for y'all sharing your experiences.}

$8: 15$ PM - 18 Oct 2016

2 Retweets 18 Likes

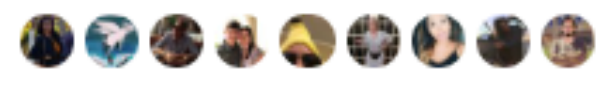

Q $\urcorner 2{ }_{2} \quad \circlearrowleft$

Figure 4. @emmyhanaway, a white student, expressing her solidarity with the tweets from her classmates of color.

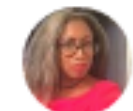

God is Found in Thick Darkness

@WilGafney

\#Being MinorityatTCU as black faculty on campus I see you and hear you. I stand with you.

5:27 AM - 19 Oct 2016

33 Retweets 155 Likes 0 i 300000

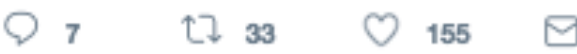

Figure 5. @WillGafney, a black faculty member, standing alongside students in the \#BeingMinorityAtTCU movement. 
However, it was obvious that students of color needed more support from TCU. From this hashtag, a group of three students (Diona Willis, Emily Laff, and Shanel Alexander) decided to create a list of fourteen demands, listed below, to introduce to campus administration to strike change on TCU's campus and continue to gauge the attention of administration. These demands were uploaded by Tamera Hyatte into a document sharing site, that was then linked into many circulated articles about the demands and \#BeingMinorityAtTCU

1. We demand that TCU revise the Code of Conduct to reflect a zerotolerance policy for racially insensitive and hateful speech. This will include developing and implementing protocol that will appropriately handle instances of hate speech as well as hate crimes involving TCU students. To do this we propose that a student led Diversity/Inclusion/Accountability board be created to focus on all issues of racial insensitivity on campus. The board will focus on initiating campus-wide conversation on diversity and inclusion on TCU's campus as well as holding students, faculty, and staff accountable for insensitivity.

2. We demand that TCU increase faculty of color by at least $10 \%$, in addition the retention rate of these faculty members will remain above $75 \%$ (to reflect the population of Texas).

3. We demand all TCU faculty, staff, and students attend a sensitivity training with a trained professional during orientation that focuses not only on racial and anti-Semitic intolerance but also micro-aggressions in order to maintain diversity and inclusion.

4. We demand accurate annual reports that reflect TCU's progress in terms of increasing diversity, not solely based on locations but also race in incoming classes as well as the diversity of all faculty and staff.

5. We demand a spark of meaningful dialogue - administrators and student media outlets must use existing communication channels to start, continue, and deepen our discussion of racism and ethnocentrism through conversations during orientation and throughout the core curriculum. In the core curriculum, focusing on the Cultural Awareness as being exclusively for the awareness of world and people.

6. We demand a one hundred million dollar endowment to further support minority students, and make TCU a more fiscally feasible option through non-athletic scholarships offered to low-income high schools not included within the realm of Community Scholars, and the creation of a multicultural center that is for students and by students. 
7. We demand that a department of diverse studies are created along with an Ethnic Studies course that will be a core curriculum requirement for all students. We also demand a rigorous reevaluation of the courses that currently fulfill the core curriculum's diversity requirement, led by a board comprised of faculty of color who would be compensated for this service.

8. We demand that TCU create a Greek-life diversity task force to implement a mandatory cultural sensitivity training, with a trained professional, for all students considering Greek life.

9. We demand housing for members of both the Multicultural Greek Council and National Pan-Hellenic Council, as they are a vital part of diversity on this campus.

10. We demand the establishment of an Asian American studies major and a Native American studies major, because they are representative of people both in the state of Texas and beyond.

11. We demand a university-funded speaker series, that focuses on diversity and how we can better implement and celebrate it on campus.

12. We demand that TCU hire a Chief Officer of Diversity and Inclusion in charge of overseeing the curriculums and projects set forth in this document.

13. We demand that the flag be lowered when people of color around the nation are murdered by people who are supposed to protect and serve.

14. We demand that the students involved in the implementation of these demands, and the faculty and staff supporting them, do not suffer negative repercussions as they engage in this process of systematic and cultural change.

It was evident that students of color wanted administration to do more than simply see their tweets. They wanted action to be taken, they wanted money to be allocated, and they wanted accountability to be ensured so that these actions would take place. These demands, as a whole, were entirely focused on the experience of students of color. However, this complete list was presented by three students on behalf on the entire student body, so most of the demands were not necessarily the opinions of most students. Because the list was never sent out to students before it was presented, and no meeting had taken place to formulate the demands, it is difficult to know the degree to which students supported the list. There are, however, parallels between the demands and the tweets using the hashtag \#BeingMinorityAtTCU. 
Demand one, for a zero-tolerance policy for racially insensitive and hateful speech, recognized that students of marginalized populations expressed moments of discrimination that occurred to them on campus while tweeting with \#BeingMinorityAtTCU with little or no justice for that discrimination. Because there is no settled definition of what counts as "racially insensitive and hateful speech," this demand for clear policy must be met first in order to create standards for inclusive language on TCU's campus. Demands two and three focused on the needs for faculty to not only receive sensitivity training, but also to be affirmed by the institution if they are working toward greater inclusivity. Although these are student-centered demands, faculty and staff members play a large role in the sense of belonging for underrepresented populations. Demands five, seven, and ten were all aimed at changes in the curriculum that would combat the lack of inclusion in academic settings, as well as push for more investment in well-trained professors. Many of the tweets that led to the formation of these demands reflected microaggressions students had experienced in classroom. Student activists suggested these microaggressive behaviors be solved by adding more academic spaces for both students of color and white students to talk about race. A combination of the lack of diversity in classrooms and proper training for professors creates a hostile learning environment for students of color. Like the post in Figure 6 , students of color are often asked to speak on behalf of their entire race, either because professors feel like that is an appropriate teaching method, or because white students associate racialized topics with people who share that identity. Creating academic expectations that encourage personal conversations, as opposed to asking students speaking out on behalf of an entire identity group, will create a more inclusive classroom setting. 


\section{Being the "black voice" that one time slavery comes up in that one class \#Being MinorityAtTCU}

7:01 PM - 18 Oct 2016

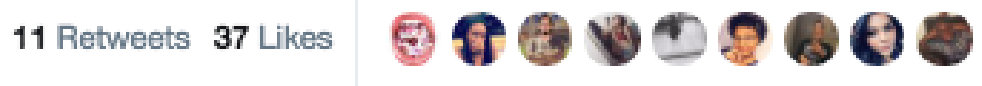

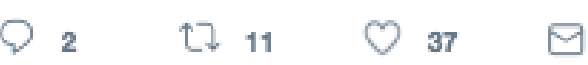

Figure 6. @_HoneyBunzz tweets about having to speak on behalf of her entire race when slavery comes up.

Figure 7 is similar to Figure 6, in the sense that many students of color are constantly asked to speak on behalf of their entire race. Even if a student is familiar with a specific topic in class, such as a country in Africa that their family may be from, they are still not able to speak on behalf of every single person who shares that identity or owns that same connection. It is more likely for students of color and students in marginalized populations to speak on behalf of a minority group because of the lack of understanding that exists in the majority population. Encouraging a more diverse curriculum, that covers content of diverse populations and skills on how to have inclusive conversations, can start to combat this issue. 


\title{
\#Being MinorityatTCU is having to answer questions about your entire continent. People, Africa is a CONTINENT, not a COUNTRY.
}

\author{
11:11 PM - 18 Oct 2016
}

12 Retweets 44 Likes

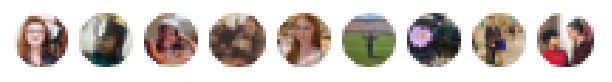

Figure 7. @jantwi_d notes the ignorance of many of her classmates that are unable to recognize that Africa is a diverse continent.

Additionally, demand number twelve encouraged the hiring of a designated Chief position to focus on diversity and inclusion to oversee the entire campus as the administration executes new DEl initiatives. This demand pairs the academic with the social, by streamlining both sides of the collegiate experience to ensure inclusive practices on all parts. Most of the other demands are specific ways that the TCU administration can dedicate more money and effort to students of color and improve the daily lives of marginalized students on campus.

The demands did spark change, but they were relatively broad and did not include tangible goals for holding TCU and the Chancellor accountable. When the demands were presented, the committee on Diversity, Equity, and Inclusion (DEI) initiatives was starting up. In an email communication from the Chancellor on October 16th 2016, he listed the following changes after meeting with the three students who proposed the list of demands, in addition to the changes that were ongoing at that moment:

1. "I will establish a Cabinet-level position to lead our efforts regarding diversity and inclusion.

2. We will provide more training for all students, faculty and staff so that they may better partner with us to affect cultural change on our campus. 
3. We will find additional ways to support students, faculty and staff of color through some of the conflict happening in our country.

4. We will continue to actively recruit a diverse student body and members of the faculty and staff who are strong role model and mentors.

Other recommendations will take the work of University committees and structures, as follows:

1. I will ask Provost Donovan to work with faculty to examine their curricula for opportunities to engage students in the scholarship of diversity and inclusion.

2. I will ask the recently established Diversity Commission to establish a Bias Response Team that will determine a campus-wide response when acts of bias occur in the community."

The solutions that the Chancellor presented only mirrored how broad the list of demands were. There were no deadlines, specific steps to be taken to achieve those goals, and a number of demands that went unaddressed, such as housing for multicultural Greek councils. In terms of curriculum, the Chancellor said he would ask Provost Donovan to work with faculty and decreased his responsibility to fulfilling this demand. Two years later, another social media movement, \#DearTCU, rose up to highlight the promises the chancellor had not completed.

\section{\#DEARTCU}

When I first came to TCU as an undergraduate student, I noticed that student activism was not visible on campus. For the most part, the homogenous population meant that the support services that TCU provided were enough for the majority of the population. As an Asian-American student, I never felt the urge to speak up about the fact that there are little to no resources for this student demographic because I did not think that other people felt the same way. Then, when \#BeingMinorityatTCU happened my sophomore year, I realized that there were students who were experiencing this same feeling. For the first time, I knew that I could advocate for myself with the support of other marginalized students by my side. It was time that we demanded administration to recognize that we belonged on TCU's campus.

The Justice Coalition was developed from a class project into a coalitionbuilding alliance on TCU's campus, created to foster action through enhancing 
student voice. This class, the Justice Journey, focused on the details behind the organizing that shaped the Civil Rights Movements. The Justice Coalition was created with those organizing methods in mind, including adopting the use of "mass meetings," which are community gatherings. TCU mass meetings, often held on campus and hosting over fifty students at a time, were held to gather student intel on what TCU needed to do differently. These meetings were able to provide insight about what students, who had a passion for social justice, wanted changed on TCU's campus; most of the conversations circulated around the idea of changing the core curriculum so that students would be required to take a course about diversity and inclusion before graduating, a conversation that had been happening ever since \#BeingMinorityAtTCU brought it up years before. 


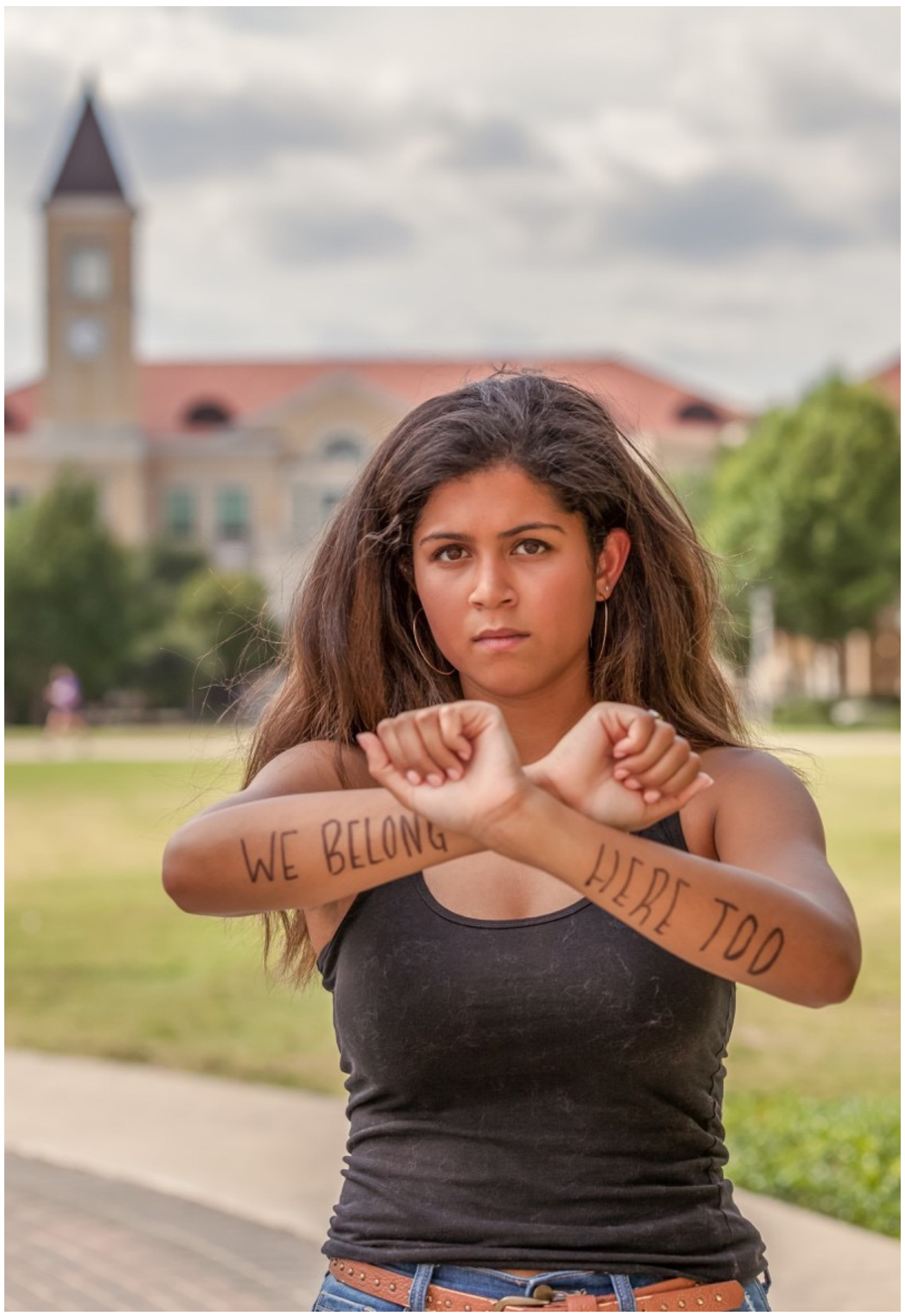




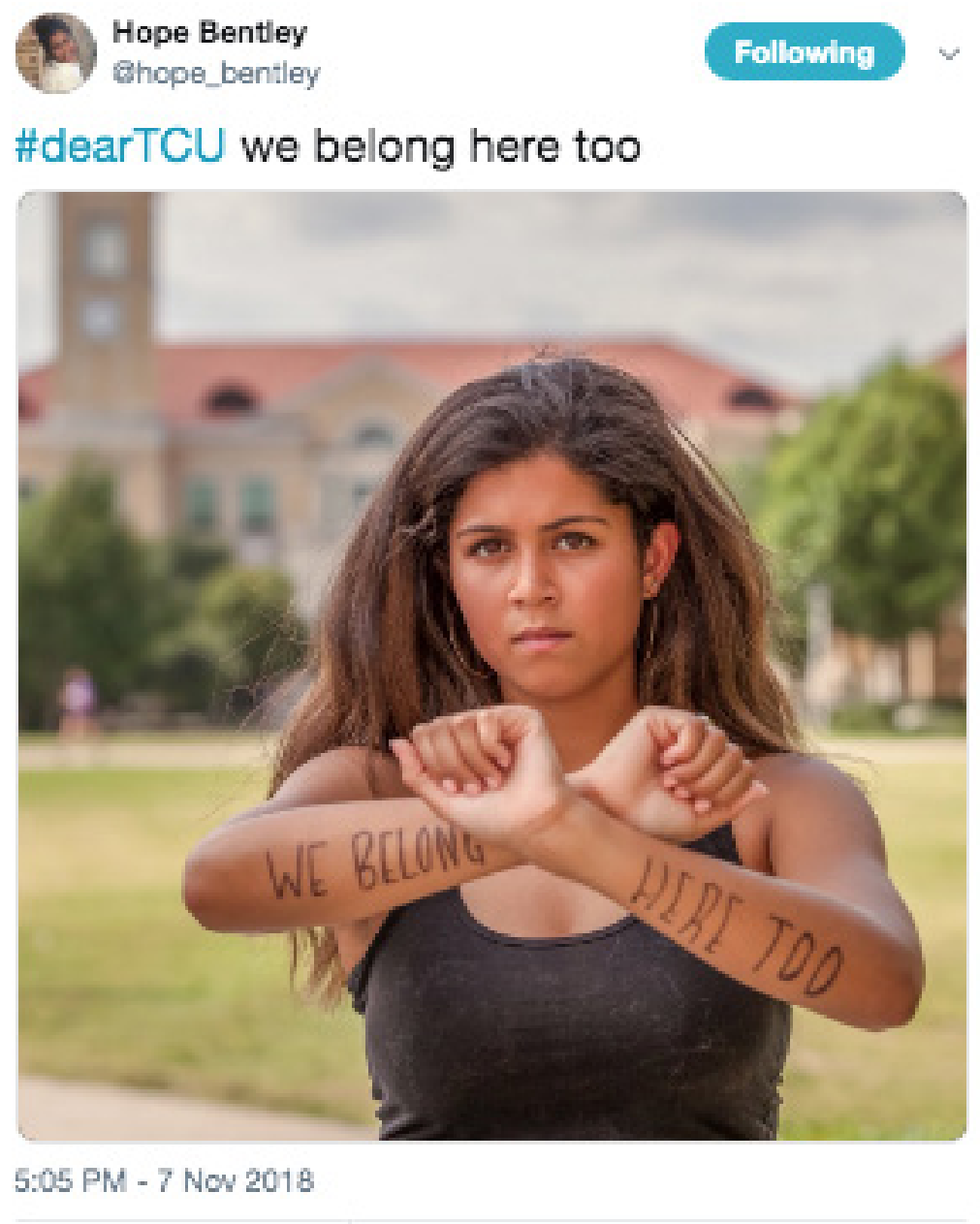

58 Retweets 272 Likes 1609200

Figure 8. @hope_bentley utilizing her experience and standing alongside other marginalized groups to fight for sense of belonging of these students.

Around the same time that the list of demands came out, the campus-wide Diversity, Equity, and Inclusion (DEI) committee was starting up, composed of a majority of staff and faculty who are passionate about and trained in addressing these issues. A subcommittee of this larger DEI committee covered curriculum, which is where Hope Bentley, a fellow TCU undergraduate student, and I planted ourselves to start to create the DEI core component proposal. Hope and I are both part of the Chancellor's Leadership Program, a social change cohort-based program on campus, which features a senior legacy project component. Typically, 30-35 first-year students are accepted into this 
program every year, creating a close-knit group of individuals passionate about social change. The range of projects has included partnerships with local nonprofit organizations, donation drives, and mentoring programs implemented in local high schools for men of color. For a long time. Hope and I discussed the possibility of implementing a large-scale curriculum change at TCU to ensure that every student has a chance to learn about some aspect of diversity, equity, and/or inclusion. The DEI committee has defined these terms on their website: diversity "reflects a broad range of identities and perspectives," equity "is creating opportunities for equal access and success for historically underrepresented populations" requiring "proactive steps," and inclusion "exists when all members of a community feel welcome, respected, and valued regardless of their social identities and when all experiences and cultures are validating and cherished equally." This committee was the perfect place for us to start on our big idea of creating curriculum changes. A large concern of the committee was making sure that students were on board with this potential change in the core curriculum, which is where Hope and I were able to productively intervene. The committee expressed the importance of showing that students are interested in social justice work. Student interest helps to ensure that administration and faculty buy into the changes as well. If students are fighting for change, and are taking responsibility for being part of the process that mainly affects students, then other stakeholders would be more likely to support this shift. In order to show student support, we planned the \#DearTCU social media movement for the students who refuse to be invisible (Figure 9). 


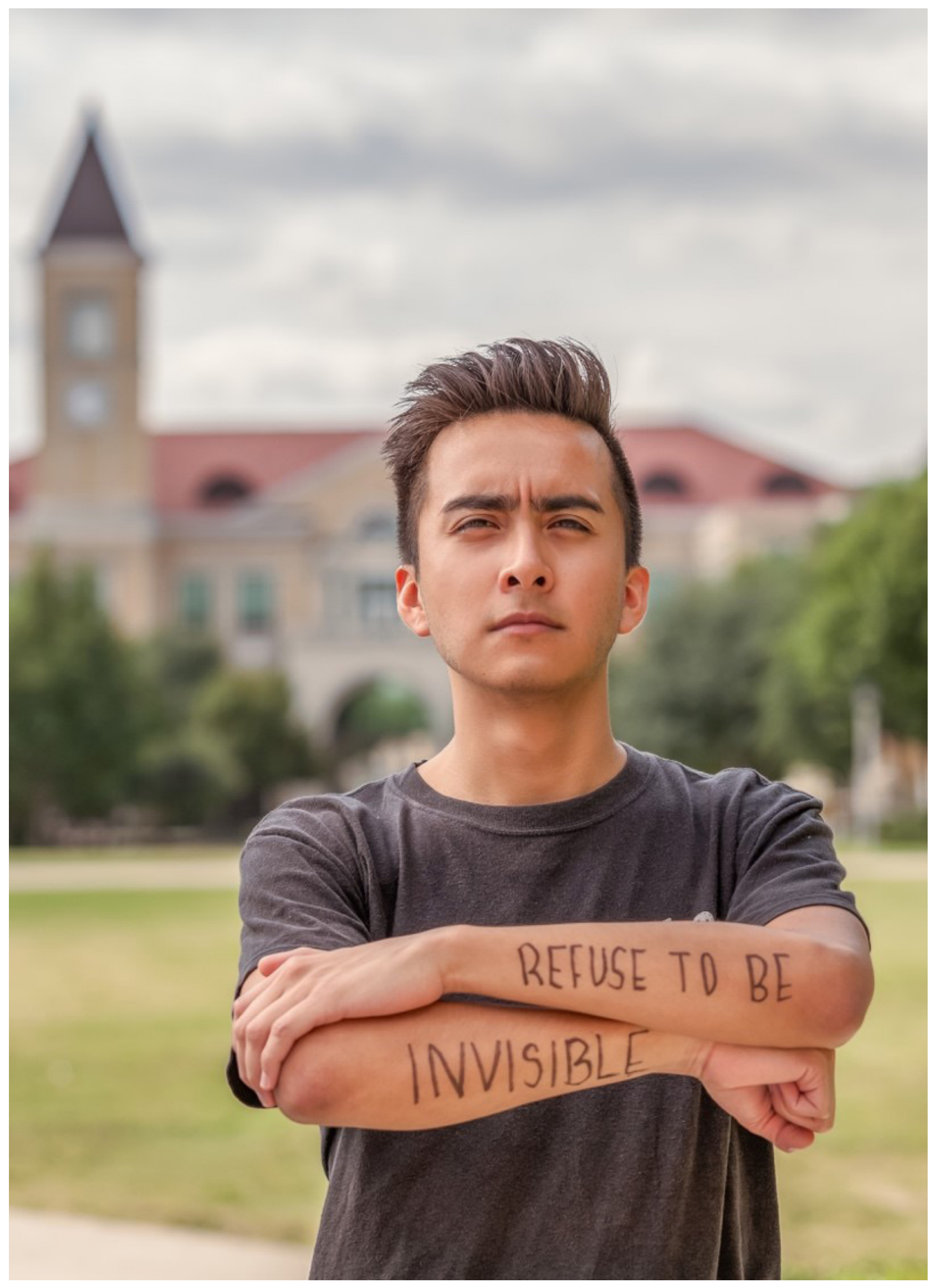



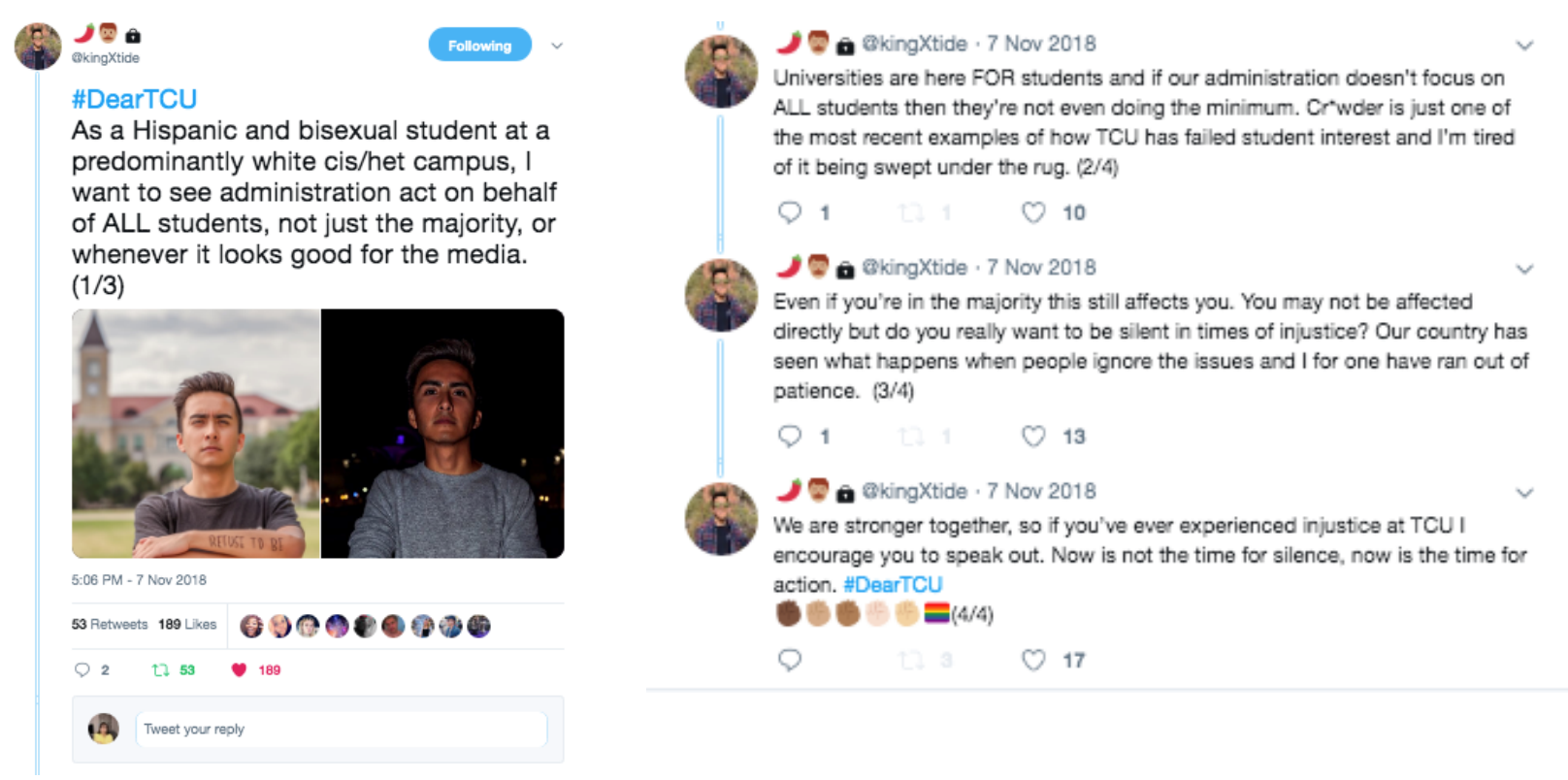

Figure 9. @kingXtide literally and figuratively refusing to be invisible by posting this as a form of protest against TCU administration.

Reflecting back on the "hidden curriculum," Esposito wrote about the hyper-visibility of students of color (2016). This hyper-visibility is, interestingly, contradicted by a sense of invisibility that also exist among communities of color because of a lack of respect. This contradiction is why images were especially important in the \#DearTCU movement; we wanted to be intentional about empowering students of color to feel visible by posting pictures of themselves as a form of protest, while also utilizing the identifying factors that often cause students to become excluded on college campuses. In Figure 9, the student makes a statement that he does not want to feel invisible on his own campus while displaying two parts of his identity as a bisexual Hispanic male. This use of imagery forces a visibility that is defined by the student posting the picture, as opposed as being defined by majority students.

As mentioned earlier, administration can often gauge student opinion through social media activity. We also reflected on the hashtag social media movements that were common on college campuses, especially \#BBUM (\#BeingBlackAtUniversityofMichigan). If a large number of students used the hashtag \#DearTCU with concerns about TCU, we knew that administration would see this and would hopefully force a reaction of positive change, including supporting a core curriculum change. At each of the Justice Coalition 
mass meetings, we would gather contact information from attendees. We individually texted and sent emails to students who showed interest in this issue with the details of how to participate in our newest plan.

Students voluntarily participated in getting their photo taken with a block of text about their experiences as a marginalized identity on TCU's campus. We created a sense of solidarity among all students by posting at the same time, flooding the timelines of many students with uniform photos all connected with the hashtag \#DearTCU. In order to achieve the highest level of visibility, we made sure to have a set time that everyone would post so that all of these uniform photos would be blocked together. The diversity of the students who participated was reflected in the variety of captions that followed each picture. This diversity also ensured that the posts reached a wider audience than just a small convenient group of TCU students. It is imperative to have as many people aware of this movement as possible, because once individuals are exposed to the information being spread, they have no way of saying that they weren't aware of these opinions and experiences. Hashtag activism is highly accessible-both for viewership and participation. Any student can be involved, including students who might not feel comfortable showing up to an in-person event. However, a major critique of online-based activism is that it discourages individuals from actually going out and showing their presence in face-to-face forms of activism, such as protests and rallies (Ofori-Parku \& Moscato, 2018). To combat this critique, and find a good compromise, adding the images to \#DearTCU still encourages viewers to connect a physical person to the tweet or post. Similarly, many individuals posted pictures of themselves with their hoodies up to match the hashtags \#HoodiesUp and \#WeAreTrayvonMartin immediately after Trayvon Martin's killing by law enforcement. Bonilla and Rosa (2015) argue that adding the images of protestors "can become politically meaningful in the context of racialized bodies" by acting as "acts of solidarity that seek to humanize the victims of police brutality by suggesting that similar fate could befall other similar construed bodies" (p. 8). \#HoodiesUp created a metaphorical visual representation of how Martin's death affected entire communities of color, and represented how these same communities would stand in solidarity, on social media, with Martin and others who have been killed by law enforcement. The students were asked to take pictures to pair with their posts because we wanted to encourage viewers to see the faces behind these experiences and to recognize that people were being discriminated against just because of the color of their skin or parts of their identity that they cannot change. 
Faculty and staff were also tweeting using the hashtag \#DearTCU, similar to their engagements with \#BeingMinorityAtTCU, to show support for the students who participated in the movement, and to potentially join in themselves. Figure 10 recognizes a TCU employee who not only expressed support, but who also took responsibility for being part of the action by saying "we can create change together." Regardless of your position at TCU, people of color and people in marginalized populations often feel a lack of belonging in their spaces because of TCU's culture. Although this is a student-centered movement, it is important to acknowledge stakeholders who recognize the importance of the voices present in \#DearTCU.

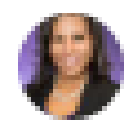

Ashley English, PhD DElavatadEC

\title{
Follow
}

So proud of students involved with the \#DearTCU campaign. Your voices matter. Your experiences matter. Your lives matter. We're listening, and we can create change together.

\author{
3:36 AM - B Nov 2016
}

10 Hetweets 43 Lkes $\quad$ 累 00900090

Figure 10. @ElevatedEC, a TCU professor, displaying pride for students tweeting with the hashtag \#DearTCU.

As mentioned earlier, a lot of diversity was represented within the movement, but it was intentional that the students who posted pictures were sharing their own personal story. Therefore, these pictures and tweets served as a call to action to peers and administration that were not aware of this exclusion until they saw these posts. The images used in \#DearTCU humanizes the experience that each participant shared in their respective posts. This was intentional, in hopes that individuals viewing the movement would feel a heightened sense of empathy when a face they recognized or had seen around 
campus before was displaying this sense of frustration with TCU. The fight for social justice is often only supported by individuals who are being oppressed, but there needs to be involvement from all sides to make lasting change (Figure 11).

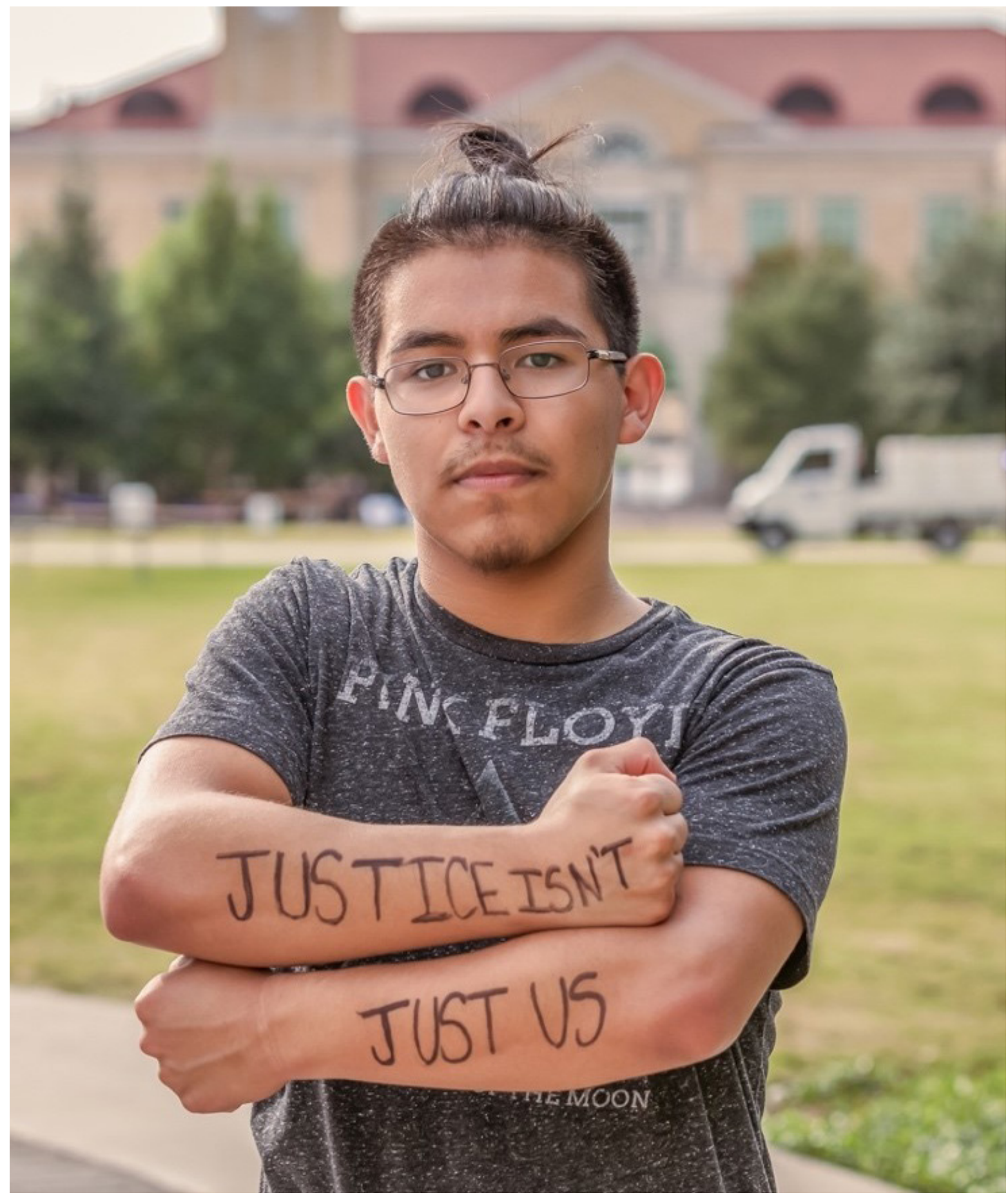


Cristian ArguetaSoto

(i) Cristian $7 \mathrm{x}$

\#DearTCU I think I speak for the majority of the students of color and a percentage of the white student body when I say that we are disappointed in how you've handled and carried yourself in the eyes of students of color. Time and time again you've advertised this campus

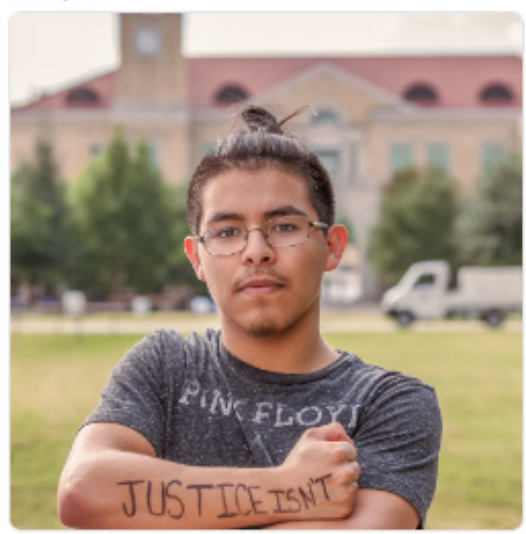

5:00 PM - 7 Nov 2018

60 Retweets 157 Lkes $5 \% 9060$

2 TCU Justioe Coalition

01 t $60 \bullet 157 \quad$ ○
Cristian ArguetaSoto @Cristian7x - Nov 7

as a diverse campus, but the fact of the matter is that it is far from that. In fact, it took me little to no time to figure out that there was only a smal percentage of students of color. I thought TCU would do a good job of representing us, but I haven't seen that yet.
Q2
t? 1
15

Cristian ArguetaSoto @Cristian 7x_ - Nov 7

For example, at the DACA rally last year higher administration refused to take our side or make a statement in support of DACA. This left DACA students feeling helpless. This is the place they call home, this is where they come to learn, but they didn't have you on their side.
Q 1
t2 3
17

Cristian ArguetaSoto @Cristian7x - Nov 7

Student body has displayed racism and stereotyping. I've been told to go back to where I came from in the middle of class. I think our staff is not trained to handle these situations. We need change implemented. "It ain't fair when you're looking for justice and it's just us."

$0 \quad$ t? $3 \quad 014$

Figure 11. @Cristian7x_calling out TCU administration and peers to ensure that the fight for justice isn't just individuals that are affected by injustice, but those that are part of the

\section{RESULTS OF HASHTAG ACTIVISM ON TCU'S CAMPUS}

\#BeingMinorityAtTCU set up a foundation to create the \#DearTCU movement, which both ended up creating change at TCU. These hashtags are tangible pieces of student support for DEl initiatives and changes which have kicked into high gear over the last few years. These hashtags are part of the efforts behind the success of the campus wide DEI committee. The https:// www.inclusion.tcu.edu website lists the following accomplishments: "The following recommendations were immediately approved:

- Establishment of Faculty Diversity Advocates in each College/School

- Establishment of the Chancellor's Postdoctoral Fellowship Program, which is dedicated to diversifying the academy 
- Launch of annual Diversity, Equity and Inclusion Award

- Increased number of incoming Community Scholars

- Establishment of STEM Scholar Program (inaugural class matriculates in summer 2018)

- Hiring of Director of Diversity and Inclusion Initiatives

- Establishment of commemorative plaque to acknowledge and pay respect to Wichita and Affiliated Tribes upon whose historical lands TCU is located. Dedication October 15, 2018.

- University membership in National Center for Faculty Development and Diversity Faculty Success Program"

Although not all of these might have been direct results of either of the hashtags mentioned in this thesis, it is imperative to recognize the urgency that developed due to the overwhelming surge of student support for most of these efforts. Through utilizing Twitter's advanced search tool, I was able to find that \#BeingMinorityAtTCU had around 3,124 interactions (retweets and likes) and \#DearTCU had around 8,587 interactions, combining to be a total of over 11,000 total interactions. These hashtags did not go unnoticed.

In addition to these successes and many more in the works, these hashtags are consistently brought up to remind students, as well as faculty and staff, of the experiences of marginalized populations; this is especially true in reference to presentations about how to make the university more inclusive, such as campus conversations about DEI in the core curriculum and celebrations for DEl awards. The effects of these social media activism campaigns have been not only to leave legacy of accountability, but also to provide an opportunity for changes in the curriculum designed to reflect the demands of many oppressed populations on campus.

There are a few reasons why these seemingly-simple hashtags were able to be part of process of institutionally changing the curriculum at TCU. The student support that was shown in \#DearTCU was part of the reason of what allowed administration and faculty/staff to recognize the importance of including a Diversity, Equity and Inclusion (DEI) component in the core curriculum. This, in addition to the work that Hope and I were doing on the subcommittee, created a transparent lens into the perspectives of students on this overall change. The hashtags paired well with the Student Government Association's resolution to support DEI in the core curriculum. The resolution was presented to the entire faculty population to vote on adding DEI in the core curriculum. The resolution eventually passed-with around $77 \%$ of faculty 
voting yes (Boser, 2019). DEl in the core curriculum will be implemented in the near future so that every single TCU student will have to take a course that meets the DEl requirements, which are still being edited at the time of this writing. Although hashtag activism is often criticized for being a minimal effort towards resistance, this narrative reveals how online activism can lead to, and pair well with, in-person forms of protest, and still end up at tangible change.

Twitter and other forms of social media are appealing to college-aged students because they open up an opportunity to broach difficult topics and have conversations that might be harder to have in person than through an online platform. If a student does not feel like they belong on a college campus, turning to social media might allow them to be more candid about their experience with more comfort (Cumberbatch \& Trujillo-Pagan, 2016). Their voluntary decision to participate in the movement reflects this idea of "participatory politics," where youth are able to develop "their own political socialization through their experiences" (Earl, et. al, 2017, p. 3). Each student who voluntarily joined in on the hashtag activism happening at TCU in the past few years represents individuals who input their voices and their own experiences into the overall conversation.

Hashtag activism provides this option to "restory." Stronaiuolo and Thomas (2017) describe "restorying" as "young people's counternarrative work to be a central mechanism for disrupting normative and deficitizing frameworks" (p. 351). At TCU, it was essential for students to use social media as a step to gain power and to raise their voices about their experiences. TCU typically markets itself as "diverse," where students of color feel like they belong. They have a branch of the university website at https://www.diversity.tcu.edu that explicitly mentions, on the welcome page, that TCU recognizes and values "the unique experiences drawn from differences in race, ethnicity, gender, sexual orientation, age, religion, and veteran status." The reality of the situation is different than what is advertised. Utilizing social media and hashtag activism as an opportunity to "restory" the experience of marginalized students on TCU's campus has forced administration and academic powers, such as the Faculty Senate, to be introduced to the true experiences of students, especially in the classroom. During many of the sessions in which the DEI core curriculum component was being talked about, there were pictures from \#DearTCU showing in the background to remind viewers and listeners of the level of student support in this initiative. Changes for DEl can often move slowly, but it is important to recognize the necessity of these changes. These are urgent 
concerns that are affecting our students now, and \#DearTCU was utilized to speed along the process of change.

TCU is an institution of higher education, where the purpose to "educate individuals to think and act as ethical leaders and responsible citizens in the global community." Still, the question is constantly being asked-Is TCU doing that? How is TCU taking strides towards ensuring that their graduates are ethical leaders and responsible citizens in the global community? It's not enough to recruit more students from diverse backgrounds. The university must also provide more opportunities for conversations about difference to come up. Figure 12 brings up how diversity is not always inclusion. TCU has made efforts to increase diverse populations, such as increasing the amount of Community Scholars and using the Lead On campaign to target students of color to come to TCU, but an increase in diversity is not beneficial to the university if nothing is being done to foster and celebrate those differences. 


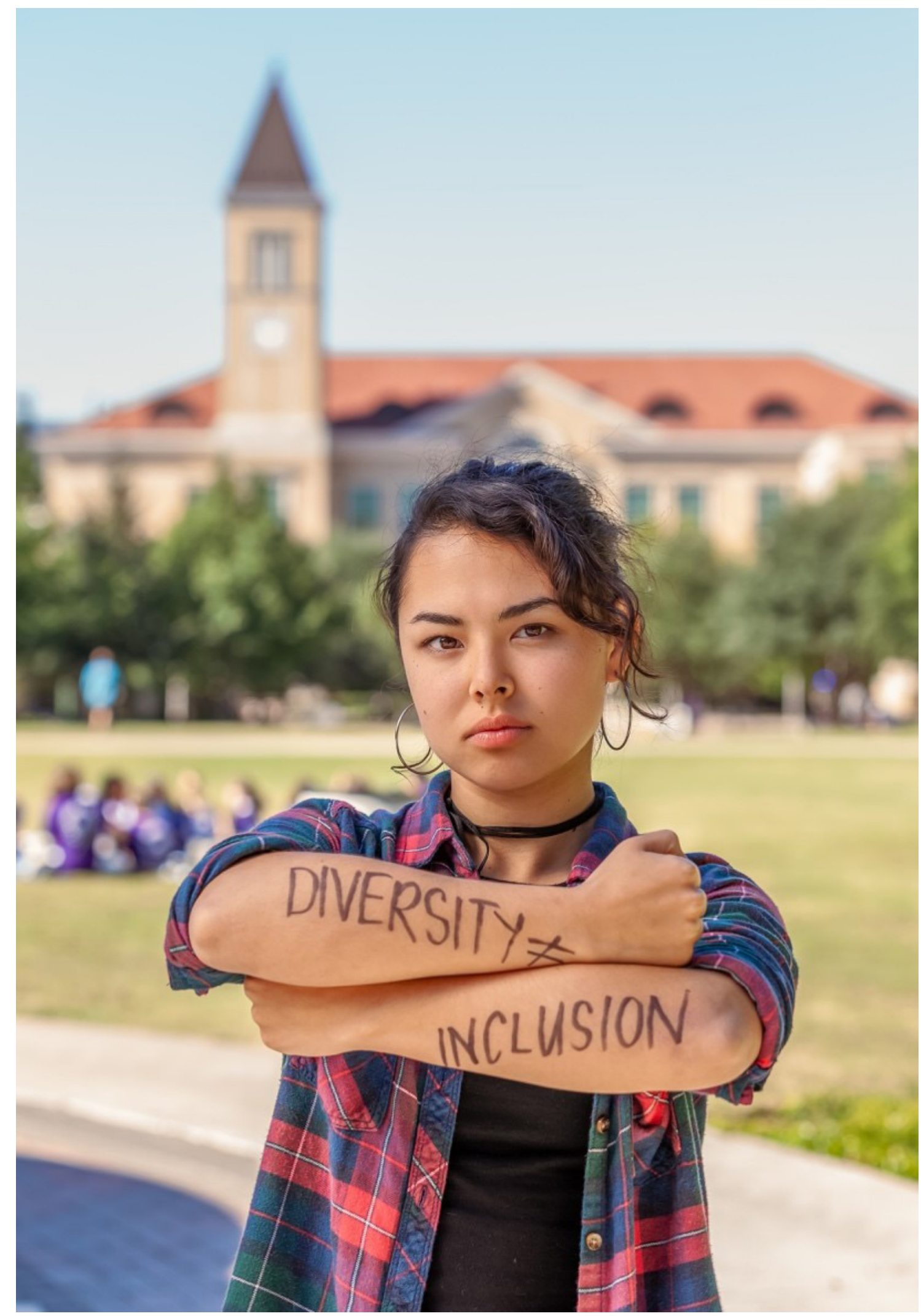




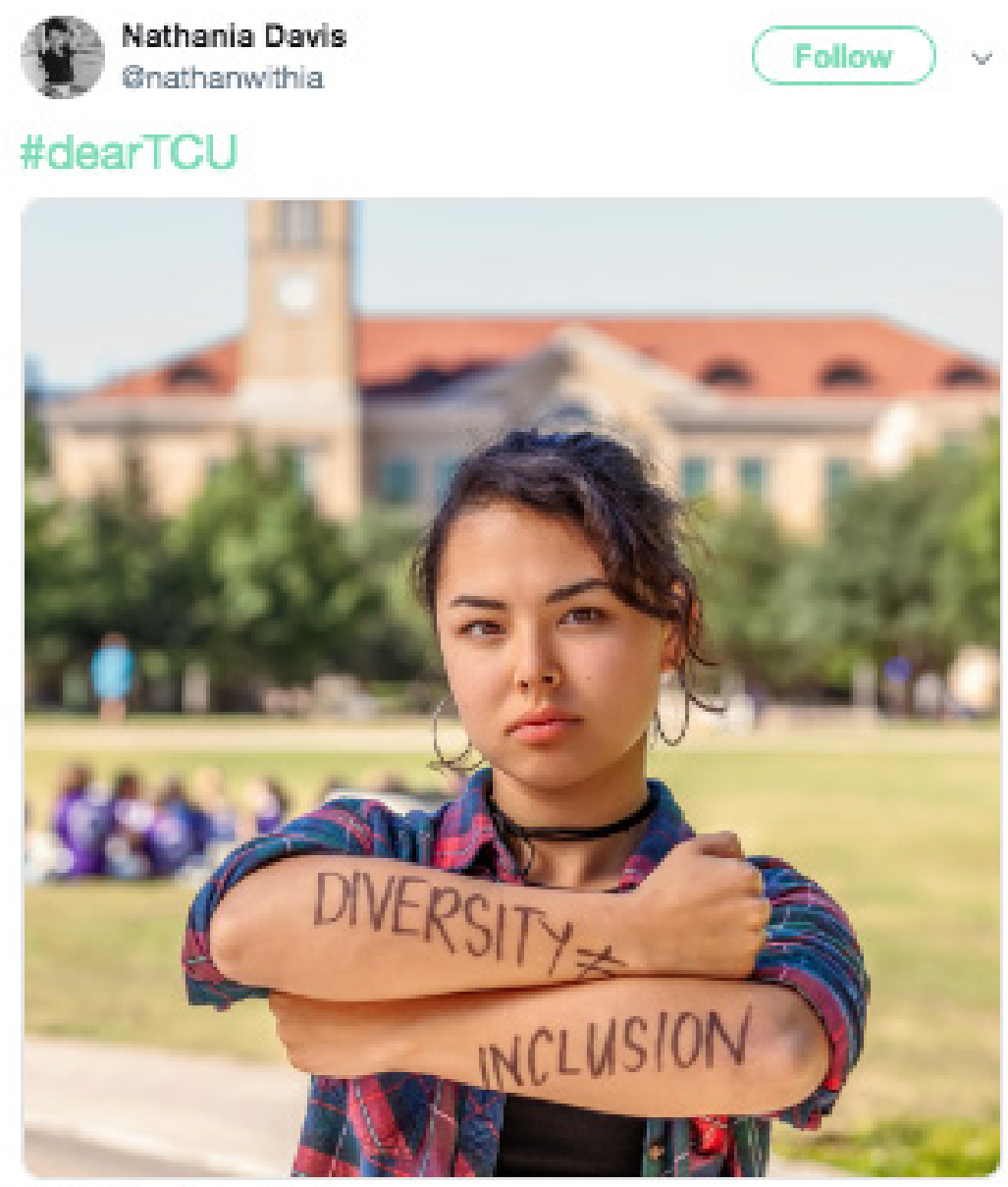

5:03 PM - 7 Nov 2018

39 Retweets 111 Likes 9000000

Figure 12. @nathanwithia using her \#DearTCU picture as an opportunity to tell TCU that the increase in diversity does not always make it feel more inclusive for those diverse populations.

Through shedding light onto the student experience, specifically in the form of hashtag activism, TCU administration was able to see the realities of the experiences of many students who may have not been seen otherwise. This is evident in \#DearTCU when TCU's official Twitter account responded to every single tweet using the hashtag. All of these posts and images come together to provide evidence of ways students need to feel more supported by TCU-one of these ways being the addition of a DEl component into the core curriculum. Through engaging student voice through avenues that feel more comfortable to them, and meeting students in spaces where they are already organizing, 
TCU is able to gauge student opinion over specific topics. The data from both \#BeingMinorityAtTCU and \#DearTCU, in addition to the steps that were already brewing for more inclusive curriculum at TCU, students were able to empower themselves and others to be part of large institutional changes on their college campus. 


\section{REFERENCES}

(2016). List of Demands. Retrieved from https://www.scribd.com/ document/327816349/List-of-Demands\#from_embed

(2018). TCU Fact Book. Retrieved from http://www.ir.tcu.edu/factbooks/2018

Bonilla, Y., \& Rosa, J. (2015). \#Ferguson: Digital protest, hashtag ethnography, and the racial politics of social media in the united states. American Ethnologist, 42(1), 4-17.https://anthrosource.onlinelibrary.wiley.com/doi/ abs/10.1111/amet.12112

Boser, T. (2019, March 28). Majority of faculty votes yes on DEI ballot. TCU 360. https://www.tcu360.com/2019/03/majority-of-faculty-votes-yes-on-deiballot/

Cumberbatch, P., \& Trujillo-Pagan, N. (2016). Hashtag activism and why \#BlackLivesMatter in (and to) the classroom. Radical Teacher, 106(106). https://radicalteacher.library.pitt.edu/ojs/index.php/radicalteacher/article/ view/302

Earl, J., Maher, T.V., \& Elliot, T. (2017). Youth, activism, and social movements. Sociology Compass, 17(4). https://doi.org/10.1111/soc4.12465

Esposito, J. (2011). Negoiating the gaze and learning the hidden curriculum: A critical race analysis of the embodiment of female students of color at a predominately white institution. Journal for Critical Education Policy Studies, 9(2). https://eric.ed.gov/?id=EJ960609

Fleming, A. R., Oertle, K. M., Plotner, A. J. \& Hakun, J. G. (2017). Influence of social factors of student satisfaction among college students with disabilities. Journal of College Student Development, 58(2), 215-228. https://doi. org/10.1353/csd.2017.0016

Haverstick, B. (2018, November 7). Students address diversity and inclusion in 'Dear TCU' campaign. TCU 360. https://www.tcu360.com/2018/11/dear-tcucampaign-to-bring-diversity-awareness/ 
Hyatte, T. (2016, October 18). Organizers of protests release list of demands. TCU 360. https://www.tcu360.com/2016/10/the-organizers-of-the-protestsrelease-list-of-demands/

Hyatte, T. (2016, October 19). \#Being MinorityatTCU goes viral on Twitter. TCU 360. https://www.tcu360.com/2016/10/beingminorityattcu-goes-viral-ontwitter/

Minikel-Lacocque, J. (2013). Racism, college, and the power of words: Racial microaggressions reconsidered. American Educational Research Journal, 50(3), 432-465. https://doi.org/10.3102/0002831212468048

Murthy, D. (2012). Towards a sociological understanding of social media: Theorizing twitter. Sociology, 46(6), 1059-1073. https://doi. org/10.1177/0038038511422553

Noland, A. (2017). (Unpublished dissertation.) James Madison University. Clicks, likes and shared: Using the theory of planned behavior, self-efficacy,and impression management to predict digital activism activities. http://orcid. org/0000-0002-6857-0275

Ofori-Parku, S., \& Moscato, D. (2018). Hashtag activism as a form of political action: A qualitative analysis of the \#BringBackOurCirls campaign in Nigerian, UK, and US press. International Journal of Communication, 12, 2480-2502. https://ijoc.org/index.php/ijoc/article/view/8068

Sommers, S. R., Apfelbaum, E. P., Dukes, K. N., Toosi, N., \& Wang, E. J. (2006). Race and media coverage of hurricane katrina: Analysis, implications, and future research questions. Analyses of Social Issues and Public Policy, 6(1), 39-55. https://doi.org/10.1111/j.1530-2415.2006.00103.x

Spencer, S. J., Logel, C., \& Davies, P. G. (2016). Stereotype threat. Annual Review of Psychology, 67(1), 415-437. https://doi.org/10.1146/annurevpsych-073115-103235

Stornaiuolo, A., \& Thomas, E. E. (2017). Disrupting educational inequalities through youth digital activism. Review of Research in Education, 47(1), 337357. https://doi.org/10.3102/0091732X16687973 
Van Dyke, N., \& Tester, G. (2014). Dangerous climates: Factors associated with variation in racist hate crimes on college campuses. Journal of Contemporary Criminal Justice, 30(3), 290-309. https://doi. org/10.1177/1043986214536666

Yang, G. (2016). Narrative agency in hashtag activism: The case of \#BlackLivesMatter. Media and Communication, 4(4), 13-17. http://dx.doi. org/10.17645/mac.v4i4.692 